\title{
Frequency of Hypovitaminosis D in 6 - 59 Month Children with Severe Malaria in the Pediatrics Unit of the Teaching Hospital of Parakou (CHUD/BA) in Benin in 2016
}

\author{
Alphonse Noudamadjo1* ${ }^{*}$, Julien Didier Adédémy', Joseph Agossou' ${ }^{1}$, Gratien Godonou Sagbo², \\ Falilatou Agbeille1, Gérard Kpanidja1', Jacques Assoklé1, Simon Akpona1 \\ ${ }^{1}$ Faculty of Medicine, University of Parakou, CHUD/BA, Parakou, Benin \\ ${ }^{2}$ Faculty of Health Sciences of Cotonou, Cotonou, Benin \\ Email: *alphonse_ndama@yahoo.fr, kofadier@yahoo.fr, agossoujoseph@gmail.com, godsagbo@yahoo.fr, fmagbeille@yahoo.fr, \\ kpanidjagerard@yahoo.fr, jacquesassokle@yahoo.fr, a kponasimon@yahoo.fr
}

How to cite this paper: Noudamadjo, A., Adédémy, J.D., Agossou, J., Sagbo, G.G., Agbeille, F., Kpanidja, G., Assoklé, J. and Akpona, S. (2018) Frequency of Hypovitaminosis D in 6 - 59 Month Children with Severe Malaria in the Pediatrics Unit of the Teaching Hospital of Parakou (CHUD/BA) in Benin in 2016. Open Journal of Pediatrics, 8, 66-73.

https://doi.org/10.4236/ojped.2018.81009

Received: January 1, 2018

Accepted: March 9, 2018

Published: March 12, 2018

Copyright (c) 2018 by authors and Scientific Research Publishing Inc. This work is licensed under the Creative Commons Attribution International License (CC BY 4.0).

http://creativecommons.org/licenses/by/4.0/ c) () Open Access

\begin{abstract}
Introduction: Vitamin D's action outside of bone, especially on immunity, is widely reported in the international scientific literature over the last years. Objective: Calculate the frequency of hypovitaminosis D in children aged 6 to 59 months suffering from severe malaria in the CHUD-P pediatric unit in 2016. Setting and Methods: This research work is a cross-sectional study with descriptive and analytical purposes. Data gathering was prospective. The study involved children aged 6 to 59 months hospitalized for severe malaria in the CHUD-P pediatric unit. The said children were HIV-uninfected, eutrophic and had not received vitamin D supplementation during the last 6 months. Vitamin D dose was measured using the High Performance Liquid Chromatography (HPLC) technique. Results: A total of 80 subjects were involved in the survey. Mean age was 26.08 months, sex ratio was 0.8 and average weight was $10.80 \mathrm{~kg}$. Hypovitaminosis D frequency was $83.8 \%$ (67 cases out of 80 children investigated during the survey) with an average plasma concentration of vitamin $\mathrm{D}$ estimated at $21.57 \mathrm{ng} / \mathrm{ml} \pm 7.34$ with two extremes (11.24 42.32) $\mathrm{ng} / \mathrm{ml}$. The minimum parasitaemia was $202 \mathrm{P} / \mu \mathrm{l}$ and the maximum was $580,000 \mathrm{P} / \mu$ l. Conclusion: Hypovitaminosis $\mathrm{D}$ is common in children suffering from severe malaria; this result suggests conducting a large-scale community-based study to decide on vitamin $\mathrm{D}$ inclusion in national supplementation policies and severe malaria management.
\end{abstract}

\section{Keywords}

Hypovitaminosis D, Severe Malaria, Children, Benin 


\section{Introduction}

As sunshine is significant in the Sub-Saharan Africa, hypovitaminosis should be exceptional. However, some factors (dark skin color, poor nutritional intake) are likely to predispose children to vitamin D deficiency which may, if appropriate, contribute to morbidity and mortality due to malaria given the said vitamin's role in the immune system [1] [2] [3]. Malaria is the first killer of the under five years children in Benin [4] and publications on the role of hypovitaminosis in malaria exist [5]. This research work aimed to determine the frequency of hypovitaminosis D in children aged 6 to 59 months hospitalized for severe malaria in the CHUD-P pediatric unit in 2016.

\section{Patients and Methods}

It was a descriptive cross-sectional study carried out both in the pediatric unit of the Regional University Teaching Hospital of Parakou (CHUD-P) and in the Laboratory of Pharmacognosy and Essential Oils (LAPHE) of Porto-Novo. The study population consisted of children hospitalized in the CHUD-P pediatric unit for severe malaria. The study included children aged 6 to 59 months hospitalized for severe malaria, HIV-uninfected, eutrophic and who had not received any vitamin $\mathrm{D}$ supplementation during the last 6 months. It excluded eligible children whose parents refused to participate to the study. The major variable in study was the serum vitamin D concentration and the others variables were the sociodemographic and behavioral characteristics.

Vitamin D was measured using the technique of High Performance Liquid Chromatography (HPLC) on a sample of $2.5 \mathrm{ml}$ of serum stemming from blood centrifugation. That serum had been stored at a $+4^{\circ} \mathrm{C}$ temperature and carried under the same storage conditions to LAPHE in Porto-Novo. Severe malaria diagnosis was established in accordance with the WHO criteria [6]. Severe anemia has been defined as hemoglobin level of less than $5 \mathrm{~g} / \mathrm{dL}$. Hypoglycemia was defined as a blood glucose lower than $40 \mathrm{mg} / \mathrm{dL}$ and hemolysis as the presence of hemoglobin in the urine, detected by self-test strip.

The thresholds to define the different conditions related to vitamin D levels in the human body are indicated in the Table 1 below.

The collected data were processed and analyzed using Epi Info software version 7 .

The administrative authorities approved the conduct of the study. The data were collected on anonymity with due regard to privacy and confidentiality. The fact that a parent refused to participate to the study had no incidence on the quality of care provided to their child. Besides, vitamin D dosage and management of hypovitaminosis cases diagnosed were free of charge for parents.

\section{Results}

From May to July 2016, eighty (80) hospitalized cases of severe malaria who met inclusion criteria were registered for this study. 
Table 1. Technical definition of the different conditions related to plasma levels of vitamin $\mathrm{D}$ in the human body [7].

\begin{tabular}{ccc}
\hline & $\mathrm{ng} / \mathrm{ml}$ & $\mathrm{nmol} / \mathrm{l}$ \\
\hline Normal & $30-100$ & $75-250$ \\
Hypovitaminosis & $<30$ & $<75$ \\
Mild deficiency or insufficiency & $20.8-30$ & $52-75$ \\
Moderate deficiency & $12-20.8$ & $30-52$ \\
Severe deficiency & $<12$ & $<30$ \\
Undetectable vitamin D & $<4$ & $<10$ \\
Excess & $>100$ & $>250$ \\
Intoxication & $>150$ & $>375$ \\
\hline
\end{tabular}

\subsection{Description of Population According to Its Sociodemographic and Behavioral Characteristics}

\subsubsection{Sociodemographic Characteristics}

\section{Age, sex and rank among siblings}

In our cohort, patients' mean age was $26.08 \pm 13.16$ months, from 7 to 59 months. Among the 80 children, 44 were females (55\%) and 36 males (45\%); sex-ratio was 0.8 .

Among siblings, children came first, second, third or ranked lower than third in $13.8 \%, 26.2 \%, 22.5 \%$ and $37.5 \%$ of cases respectively.

\section{Environment of residence and educational status}

The 80 children involved in this study lived in rural areas in $73.8 \%$ of cases, and $26.2 \%$ of them in town. In $72.5 \%$ of cases, mothers were uneducated. They had primary school, secondary school and higher education level in respectively $6.3 \%, 2.5 \%$ and $2.5 \%$ of cases. Eventually, they were literate in local languages in $16.2 \%$ of cases.

\subsubsection{Behavioral Characteristics}

Duration of exclusive breastfeeding (AME), weaning age and type of snack

Among the eighty (80) children included in the study, 53.8\% were exclusively breastfed for a period of less than six (6) months, $10 \%$ benefitted from a fruit juice as snack.

Table 2 shows the distribution of children involved in the study according to duration of breastfeeding, weaning age and type of snack.

Clinical and biological features

Almost two out of three children had severe anemia as a sign of severity. The minimum parasitaemia was $202 \mathrm{P} / \mu \mathrm{l}$ and the maximum was 580,000 $\mathrm{P} / \mu \mathrm{l}$. Table 3 shows the distribution of children surveyed according to signs of malaria severity and parasitaemia.

Plasma levels of vitamin D and hypovitaminosis D frequency 
Table 2. Distribution of 6 - 59 month children hospitalized for severe malaria in the CHUD-P pediatric unit, according to duration of breastfeeding, weaning age and type of snack, in 2016.

\begin{tabular}{ccc}
\hline & Population size & Percentage (\%) \\
\hline Duration of exclusive breastfeeding $(\mathbf{n}=\mathbf{8 0})$ & 43 & 53.8 \\
$<6$ months & 37 & 46.3 \\
$\geq 6$ months & & \\
Definitive weaning age $(\mathbf{n}=\mathbf{6 0})$ & 11 & 18.3 \\
$\leq 6$ months & 06 & 10.0 \\
$6-12$ months & 21 & 35.0 \\
$12-18$ months & 22 & 36.7 \\
$>18$ months & & \\
Type of snack $(\mathrm{n}=\mathbf{8 0})$ & 08 & 10.0 \\
Fruit juice & 72 & 90.0 \\
Other & & \\
\hline
\end{tabular}

Table 3. Distribution of 6 - 59 month children hospitalized for severe malaria in the CHUD-P pediatric unit, according to signs of malaria severity and parasitaemia in 2016.

\begin{tabular}{ccc}
\hline & Population size & Percentage (\%) \\
\hline Signs of malaria severity $(\mathbf{n}=\mathbf{8 0})$ & 52 & 65.0 \\
Severe anemia & 23 & 28.8 \\
Seizure & 01 & 01.3 \\
Coma & 05 & 3.6 \\
Hemolysis & 01 & 1.3 \\
Hypoglycemia & & \\
Parasite density & 66 & 82.5 \\
$<50000 \mathrm{P} / \mu \mathrm{L}$ & 04 & 05.0 \\
{$[50,000-100,000 \mathrm{P} / \mu \mathrm{L}]$} & 09 & 11.5 \\
{$[100,000-500,000 \mathrm{P} / \mu \mathrm{L}]$} & 01 & 01.0 \\
$\geq 500,000 \mathrm{P} / \mu \mathrm{L}$ & & \\
\hline
\end{tabular}

Average plasma concentration of vitamin $\mathrm{D}$ in all the involved children was $21.57 \mathrm{ng} / \mathrm{ml} \pm 7.34$. Figure 1 shows the distribution of involved children according to their plasma levels of vitamin D.

Among the eighty (80) children, sixty-seven (67) suffered from vitamin D deficiency, i.e. an $83.8 \%$ frequency with CI [73.8 - 91.1]. Figure 2 shows the distribution of involved children according to their status as regards vitamin D.

\section{Discussion}

\subsection{Validity of Findings}

The prospective character of this study helped limit missing data during collection. 


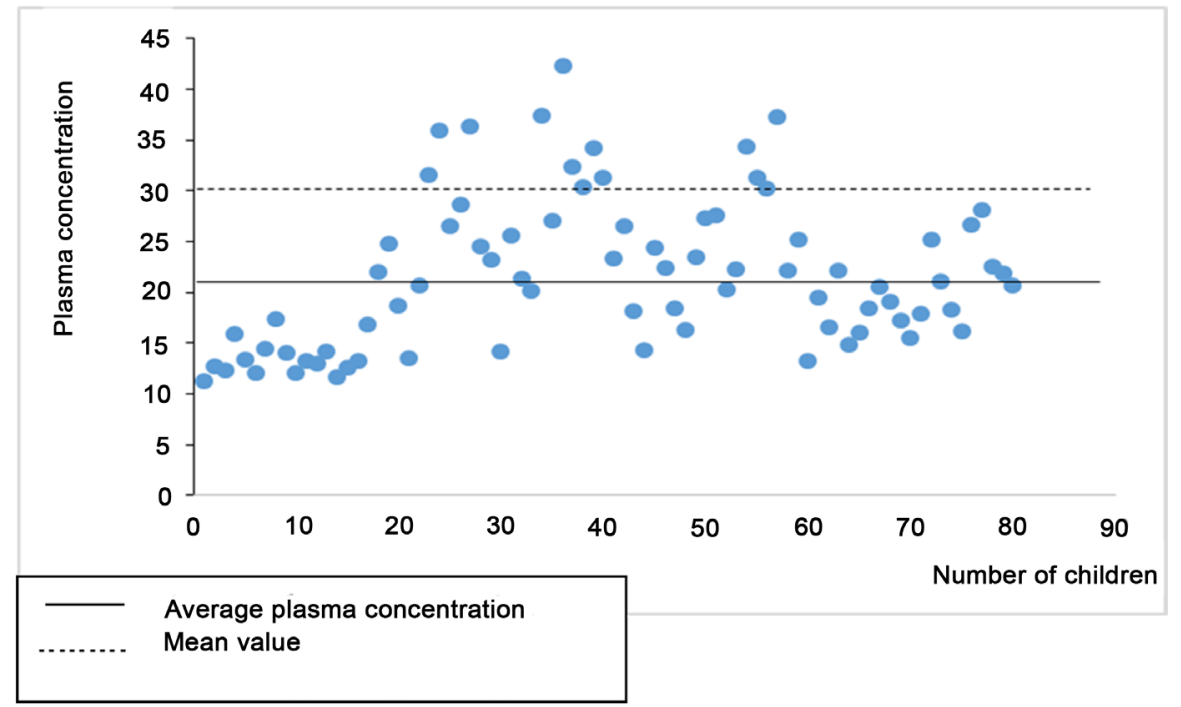

Figure 1. Plasma levels of vitamin D of 6 - 59 month children hospitalized for severe malaria in the CHUD-P pediatric unit in 2016.

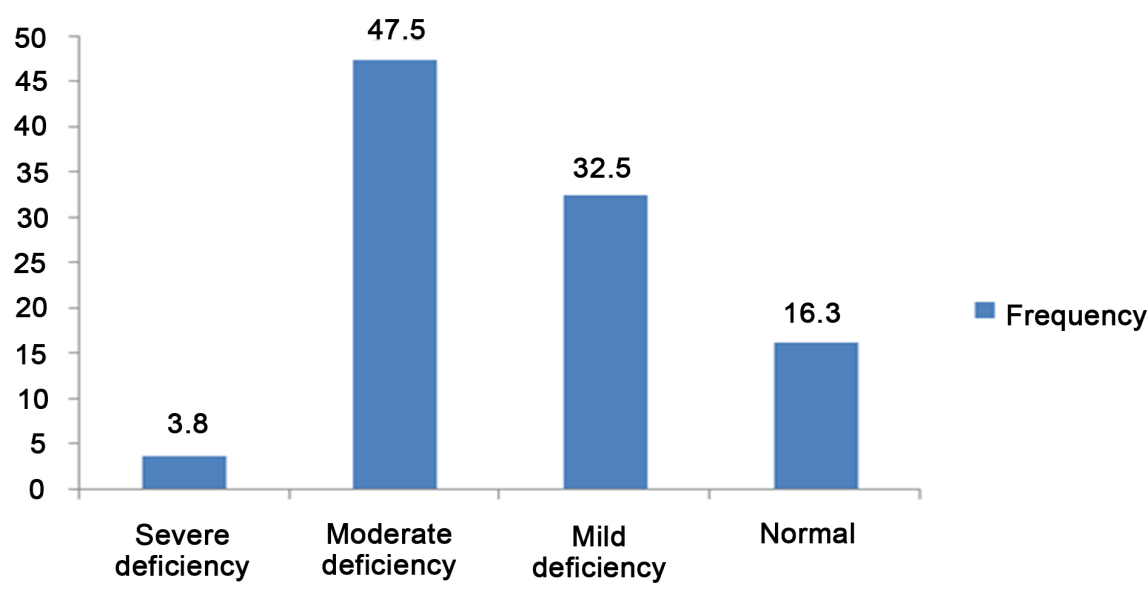

Figure 2. Distribution of 6 - 59 month children hospitalized for severe malaria in the CHUD-P pediatric unit in 2016 according to their vitamin status.

Vitamin D dosage was performed using the technique of High Performance Liquid Chromatography (HPLC). That method is currently recommended by the French High Authority of Health (HAS) for vitamin D dosage because of its innocuous nature for the person who performs it and its cost which are different from those of radio-immunologic methods. The method using HPLC technique enables to:

- separate the different isomers of vitamin D with or without biological activities,

- not modify the molecule structure, hence the possibility of additional control at the end of the chromatographic column,

- have a low enough detection threshold (absorption measured in U.V. at 254 $\mathrm{nm}$ ), which help measure vitamin D amounts of approximately $1 \mathrm{UI} / 100 \mathrm{~g}$ of sample [8]. 
But it was not possible to perform some immunological and biochemical tests such as dosage of TNF- $\alpha$, IL-6, IL-10, CD4, regulatory T (Treg) cells, calcium, phosphorus, parathormone (PTH), and Vitamin D binding protein (DBP) regulated by vitamin $\mathrm{D}$. Moreover, the genetic susceptibility associated with vitamin D was not taken into account in the study. In spite of those shortcomings, the study has the merit of addressing a topic that is not investigated in the context. Better still, its performance in children suffering from severe malaria may open up a range of treatment possibilities in the management of malaria and therefore in the reduction of infant and child mortality.

\subsection{Frequency of hypovitaminosis D}

At the end of the study, hypovitaminosis D frequency was $83.8 \%$ among children aged 6 to 59 months in the CHUD-P pediatric unit.

This frequency is similar to those reported (80\%) in Uganda by Sarah et al in a study conducted in 2014 among children aged 18 months with severe malaria [9].

That high frequency (83.8\%) identified in children in our research work in spite of an adequate sun exposure, emphasized by average duration of sun exposure estimated at 2.34 hours versus 10 to 15 minutes recommended and lack of relationship between vitamin D deficiency and duration of sun exposure, may be due to the combination of several factors such as:

- Darky pigmented skin which is a Ultra-Violet B ray protective screen required for endogenous synthesis of vitamin D. In addition to be a protective factor against sunburn, skin pigmentation is a leading cause of vitamin D deficiency in children, because of melanin which absorbs UVB rays [10].

- Inappropriate diet: according to the results of the Population and Health Survey conducted in Benin in 2011, prevalences of acute malnutrition and chronic malnutrition in the Borgou region were respectively $18.8 \%$ and $45.2 \%$. As the source of vitamin $\mathrm{D}$ was also exogenous, it may, through an inappropriate diet, contribute to that high prevalence of hypovitaminosis $\mathrm{D}$ [4].

- Recurrent infectious diseases, especially malaria, low respiratory tract infections and diarrhea are the leading causes of infant and child morbidity and mortality in our context [4] [11] [12].

- Variation in individual behaviors such as particular characteristics of dress habits [13] [14].

Other studies were conducted among children suspected of rickets. They were respectively carried out by Anath et al. (83.3\%) among 6-month children in 2013 in Tanzania [15], by Henry et al. (80\%) in 2015 among children aged 6 to 24 months in Uganda [16] and B. Timothy et al. (60\%) in Malawi in 2013 among 24-month children [17]. The said studies highlighted frequencies less high than those found out in our research work. As well, in Nigeria in 2000, Tom et al. [18] identified a $37 \%$ frequency in children aged 5 to 35 months developing rickets.

As the frequency of hypovitaminosis $\mathrm{D}$ is higher than the one found in those different studies carried out among children suspected of rickets, malaria can be 
considered as a larger source of hypovitaminosis $\mathrm{D}$ in children than rickets. We can also think that children involved in the study were vitamin $\mathrm{D}$ deficient without bone symptoms before developing severe malaria or that they had normal plasma concentration of vitamin $\mathrm{D}$ but depleted as severe malaria developed. In any cases, this result suggests that a community-based study should be conducted on clinically healthy children.

\section{Conclusion}

During this research work we decided to assess the frequency of hypovitaminosis $\mathrm{D}$ in children suffering from severe malaria in the CHUD-P pediatric unit in 2016. We can learn from its completion that hypovitaminosis D is common among children suffering from severe malaria in spite of elevated sunshine. The study suggests that a community-based survey should be conducted on plasma concentration of vitamin $\mathrm{D}$ in children apparently healthy in order to have a better understanding of interaction between vitamin $\mathrm{D}$ and malaria. This may open up a range of therapeutic possibilities in the preventive and curative management of malaria.

\section{Acknowledgements}

The authors are grateful to the children and their mothers for participation to the study, the workers of the Laboratory of Pharmacognosy and Essential Oils (LAPHE) of Porto-Novo (Benin)

\section{Funding}

The research work was funded by the authors.

\section{Authors' Contribution}

All the authors: for the proofreading of this article; Noudamadjo, A., Adedemy, J.D. and Agossou, J., Akpona, A.S.: for initiation, protocol drafting, writing of report and article draft; Sagbo, G.G., Agbeille, M.F. and Kpanidja, G.: for writing of report and article draft; Assokle, J.: protocol drafting, data collection and report writing.

\section{Permission from the Authors}

All the authors approved article submission for publication.

\section{References}

[1] Fraser, D.R. (1995) Vitamin D. Lancet, 345, 104-107. https://doi.org/10.1016/S0140-6736(95)90067-5

[2] He, X.Y., Yan, J., Zhu, X.T., Wang, Q.H., Pang, W. and Qi, Z.M. (2014) Vitamin D Inhibits the Occurrence of Experimental Cerebral Malaria in Mice by Suppressing the Host Inflammatory Response. Journal of Immunology, 193, 1314-1323. https://doi.org/10.4049/jimmunol.1400089

[3] Marco, C. and Angela, S. (1998) Vitamin D: A Transcriptional Modulator of the Interferon-y Gene. European Journal of Immunology, 28, 3017-3030. 
https://doi.org/10.1002/(SICI)1521-4141(199810)28:10<3017::AID-IMMU3017>3.0. CO;2-6

[4] National Institute of Statistics and Economic Analysis (INSAE) and ICF International (2013) Benin Population and Health Survey 2011-2012. INSAE et ICF International, Calverton, Maryland, USA.

[5] Luong, K. and Nguyen, L. (2015) The Role of Vitamin D in Malaria. The Journal of Infection in Developing Countries, 9, 8-19. https://doi.org/10.3855/jidc.3687

[6] World Health Organization (2015) Guidelines for the Treatment of Malaria. 3rd Edition, WHO Library, Geneva, 317 p.

http://apps.who.int/iris/bitstream/10665/162441/1/9789241549127_eng.pdf?ua=1\& $\underline{\mathrm{ua}=1}$

[7] Behzat, Ö., Şükrü, H. and Abdullah, B. (2012) Vitamin D Intoxication. Pediatrics, 54, 93-98.

[8] Mouillet, L., Luquet, F., Gagnepain, M. and Sorgue, Y. (1982) Vitamin D Dosage in Milk through High Pressure Liquid Chromatography. Le Lait, 62, 44-54. https://doi.org/10.1051/lait:1982611-6123

[9] Sarah, E., Robert, O., Troy, C., Chandy, C. and Lynda, E. (2014) Vitamin D Insufficiency Is Common in Ugandan Children and Is Associated with Severe Malaria. Plos One, 9, 1-8.

[10] World Health Organization (2015) Achieving the Malaria MDG Target: Reversing the Incidence of Malaria 2000-2015. WHO, Geneva, $44 \mathrm{p}$. http://www.who.int/malaria/publications/atoz/9789241509442/en/

[11] Guardia, G., Parikh, N., Eskridge, T., Phillips, E., Divine, G. and Sudhaker Rao, D. (2008) Prevalence of Vitamin D Depletion among Subjects Seeking Advice on Osteoporosis: A Five Year Cross-Sectional Study with Public Health Implication. Osteoporosis International, 19, 13-19. https://doi.org/10.1007/s00198-007-0456-3

[12] Victor-Daniel, A. (2015) Prescription of Vitamin D in Pediatric Care in a Survey among Tarn Medical Practitioners. Médecine humaine et pathologie.

https://dumas.ccsd.cnrs.fr/dumas-01111506/document

[13] David, H., William, H., Edgard-Marius, O. and Alain, D. (2008) Fever and Malaria in 0-5 Year Children in Benin: Do We Have Accurate Statistics? Cahier Santé, 18, 55-60.

[14] Murry, E. (2011) Vitamin D Update and New Therapeutic Perspectives. Sciences Pharmaceutiques. https://dumas.ccsd.cnrs.fr/dumas-00650330

[15] Letter, R. (2013) Prevalence and Risk Factors for Vitamin D Deficiency among Tanzanian HIV Exposed Uninfected Infants. Journal of Tropical Pediatrics, 59, 426-429. https://doi.org/10.1093/tropej/fmt028

[16] Henry, N., Josephine, K., Reuben, K., Agnes, K. and Sarah, K. (2015) Serum Vitamin D Status Children with Protein-Energy Malnutrition Admitted to a National Referral Hospital in Uganda. BMC Research Notes, 8, 418. https://doi.org/10.1186/s13104-015-1395-2

[17] Amukele, K., Soko, D., Katundu, P., Kamanga, M., Sun, J., Kumwenda, I., et al. (2013) Vitamin D Levels in Malawian Infants from Birth to 24 Months. Archives of Disease in Childhood, 98, 180-183. https://doi.org/10.1136/archdischild-2012-302377

[18] Tom, T., Philip, F., John, P., Juliana, L., Christian, I. and Gary, C. (2000) Case Control Study of Factors Associated with Nutritional Rickets in Nigerian Children. Journal of Pediatrics, 137, 367-373. https://doi.org/10.1067/mpd.2000.107527 